\title{
Double Isomerization Polymerization of Optically Active Cyclic Pseudoureas
}

\author{
Masatoshi Miyamoto and Takashi Umezawa* \\ Department of Polymer Science and Engineering, Faculty of Textile Science, \\ Kyoto Institute of Technology, Matsugasaki, Sakyo, Kyoto 606, Japan \\ * Department of Chemical and Biochemical Engineering, Faculty of Engineering, \\ Toyama University, Gofuku, Toyama 930, Japan
}

(Received October 11, 1995)

\begin{abstract}
Five optically active cyclic pseudoureas 2, i.e., $(R)$-4-ethyl-2-(1-pyrrolidinyl)-2-oxazoline (2a), $(R)-4$-ethyl2-morpholino-2-oxazoline (2b), $(R)$-4-ethyl-2-(2-isoindolinyl)-2-oxazoline $(\mathbf{2 c}),(S)$-4-isopropyl-2-(1-pyrrolidinyl)-2-oxazoline (2d), and $(S)$-4-benzyl-2-(1-pyrrolidinyl)-2-oxazoline (2e), were prepared and their cationic ring-opening polymerization was examined. The polymerization of these monomers with alkyl halides yielded poly[(1,3-diazolidin-2-one-1,3-diyl)oligomethylene]s (main-chain-type polyureas, 3) via the double isomerization polymerization pathway, while that with methyl trifluoromethanesulfonate produced polymers consisting of ( $N$-carbamoylimino)ethylene (pendant-type unit) and (1,3-diazolidin-2one-1,3-diyl)oligomethylene units due to concurrence of simple ring-opening polymerization of the 2-oxazoline moiety of 2 with double isomerization polymerization.
\end{abstract}

KEY WORDS Ring-Opening Polymerization / Double Isomerization Polymerization / Optically Active Polyurea / Cyclic Pseudourea /

Optically active polymers have received considerable attention since some of them show characteristic properties such as molecular recognition. ${ }^{1}$ There are two representative methods to prepare optically active polymers: one is the polymerization of optically active monomer and the other is asymmetric polymerization. The former method is easy to perform, but it is practical as long as the monomer can be obtained inexpensively. The latter method is applicable only to limited monomers, e.g., methacrylates and acrylamides having bulky substituents, isocyanates, and isocyanides, although it does not require optically active monomers. ${ }^{1-5}$

Optically active 2-aminoalcohols can be prepared by the reduction of natural $\alpha$-amino acids and, therefore, a variety of optically active 2-substituted-2-aminoalcohols can be obtained relatively inexpensively. Optically active 4-substituted-2-oxazolines can be induced from these aminoalcohols. It was reported that the ring-opening polymerization of these 2-oxazolines gave optically active poly $[(N$-acylimino $)$ ethylene $] \mathrm{s} .{ }^{6-8}$ However, the introduction of a substituent at the 4-position of 2-oxazoline ring induces decrease of ring-opening polymerizability: the steric effect of the substituent reduces both nucleophilicity of the monomer and electrophilicity of the propagating end. Since propagation is reaction of a monomer with an oxazolinium-type propagating species, the introduction of the substituent significantly reduces the rate of propagation. ${ }^{9-11}$ It is also well known that the introduction of substituent on the cyclic monomer generally reduces the thermodynamic advantage of the polymerization. ${ }^{12}$

Previous papers reported that the cationic polymerization of 2-(1-azacycloalkyl)-2-oxazolines (1), cyclic pseudoureas, proceeded via two different modes according to type of initiator. One is the simple ring-opening polymerization accompanying the opening of 2-oxazoline ring to give poly[( $N$-carbamoylimino)ethylene $]$ (pendant-type polyurea), which is initiated by an alkyl sulfonate. The other is so called "double isomerization polymerization (DIP)" accompanying the opening of 2-oxazoline and cyclic amine rings to produce poly $[(1,3-$ diazolidin-2-one-1,3-diyl)oligomethylene] (main-chaintype polyurea), which is initiated by an alkyl halide (Scheme 1). ${ }^{13-17}$

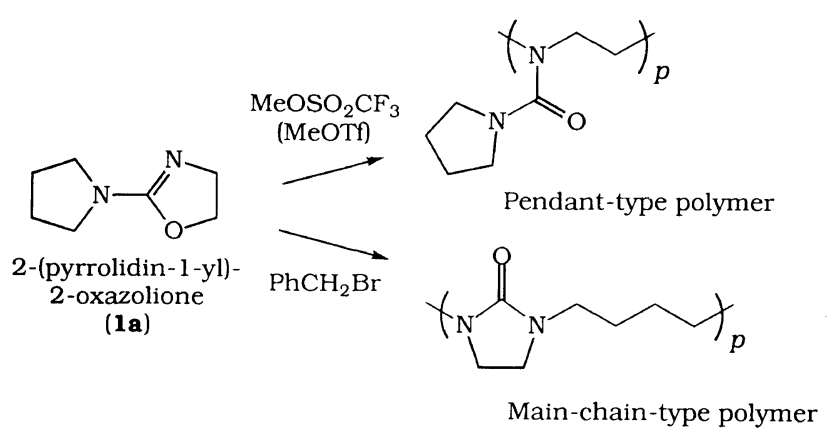

Scheme 1.

The introduction of an alkyl substituent to the oxazoline ring of cyclic pseudourea influences monomer polymerizability. However, the influence on the rate of polymerization will be smaller in DIP than in the simple ring-opening polymerization since the propagation in DIP does not include the step that the monomer attacks an 4-substituted oxazolinium-type propagating species. Propagation in DIP is the attack of the monomer to the cyclic amine derived moiety of the propagating species (see Scheme 4). Moreover, depolymerization, which frequently occurs in the ring-opening polymerization of substituted cyclic compound, will be suppressed in DIP since the polymerization accommodates an irreversible isomerization step.

The present paper deals with the preparation and cationic ring-opening polymerization of optically active cyclic pseudoureas (2) to produce optically active polyureas. The influence of the 4-substituent on both modes of polymerization is discussed. 


\section{EXPERIMENTAL}

\section{Materials}

Triethyloxonium tetrafluoroborate was prepared according to the literature. ${ }^{18} \mathrm{~L}$-Valinol and L-phenylalaninol were respectively prepared by the reduction of L-valine and L-phenylalanine with $\mathrm{LiAlH}_{4} \cdot{ }^{19}(R)-2$ amino-1-butanol was purchased from Tokyo Chemical Industry Co., Ltd. These aminoalcohols were reacted with diethyl carbonate to prepare oxazolidones (Scheme $2) .{ }^{20}$ Three 2-ethoxy-2-oxazolines, 4, $(R)$-2-ethoxy-4ethyl-(4a), (S)-2-ethoxy-4-isopropyl-(4b), and (S)-4benzyl-2-ethoxy-2-oxazolines (4c) were prepared by the ethylation of the corresponding oxazolidones with the triethyloxonium salt according to the literature. ${ }^{21}$ 2Ethoxy-2-oxazolines 4 were purified by distillation under reduced pressure. Other reagents and solvents were commercially available. They were dried by conventional methods and distilled under nitrogen. The solvents were stored over $3 \AA$ molecular sieves after distillation.

\section{Preparation of Optically Active Cyclic Pseudoureas (2)}

In a two-necked flask equipped with a magnetic stirrer bar and Dimroth condenser were placed $4.91 \mathrm{~g}$ (29.2 $\mathrm{mmol})$ of $4 \mathrm{a}, 2.37 \mathrm{~g}(31.6 \mathrm{mmol})$ of pyrrolidine, $0.60 \mathrm{~g}$ $(0.32 \mathrm{mmol})$ of $p$-toluenesulfonic acid monohydrate, and $50 \mathrm{ml}$ of benzene. The mixture was heated to reflux and heating was continued until the conversion of $\mathbf{4 a}$ traced by GLC exceeded $95 \%$. After $3 \mathrm{~h}$, the mixture was allowed to cool to room temperature and $1 \mathrm{~g}$ of sodium carbonate was added to the mixture. It was concentrated on a rotary evaporator under a reduced pressure. The residue was distilled in vacuo to yield $\mathbf{2 a}$ as transparent liquid. Yield; $3.0 \mathrm{~g}(61 \%)$.

${ }^{1} \mathrm{H}$ NMR $\left(\mathrm{CDCl}_{3}\right): 0.90\left(\mathrm{t}, \mathrm{CH}_{3}, 3 \mathrm{H}\right), 1.2-1.7(\mathrm{~m}$, $\left.\mathrm{CH}_{2} \mathrm{CH}_{3}, 2 \mathrm{H}\right), 1.7-2.0\left(\mathrm{~m}, \mathrm{NCH}_{2} \mathrm{CH}_{2}, 4 \mathrm{H}\right), 3.2-3.5$ $\left(\mathrm{m}, \mathrm{NCH}_{2}, 4 \mathrm{H}\right), 3.7-4.5\left(\mathrm{~m}, \mathrm{CH}\right.$ and $\left.\mathrm{OCH}_{2}, 3 \mathrm{H}\right) .{ }^{13} \mathrm{C}$ NMR $\left(\mathrm{CDCl}_{3}\right): 10.0\left(\mathrm{CH}_{3}\right), 25.6\left(\mathrm{NCH}_{2} \mathrm{CH}_{2}\right), 29.7$ $\left(\mathrm{CH}_{2} \mathrm{CH}_{3}\right), 47.1\left(\mathrm{NCH}_{2}\right), 66.0(\mathrm{CH}), 72.9\left(\mathrm{OCH}_{2}\right), 159.9$ $(\mathrm{C}=\mathrm{N})$. IR (neat): 2950, 2855, $1658\left(v_{\mathrm{C}=\mathrm{N}}\right), 1422,1065$, $946,962 \mathrm{~cm}^{-1}$.

$$
\mathrm{NH}_{2}^{\mathrm{R}} \mathrm{OH}+(\mathrm{EtO})_{2} \mathrm{CO} \stackrel{-2 \mathrm{EtOH}}{\longrightarrow}
$$

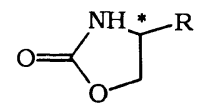

$(R)$-2-amino-1-butanol $(\mathrm{R}=\mathrm{Et})$

$(S)$-valinol $(\mathrm{R}=i \operatorname{Pr})$

$(S)$-phenylalaninol $\left(\mathrm{R}=\mathrm{CH}_{2} \mathrm{Ph}\right)$

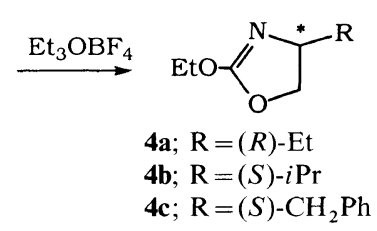

Scheme 2.
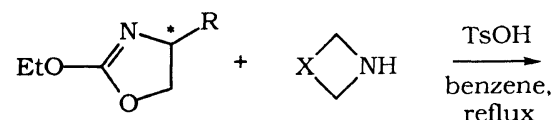

$$
\begin{array}{lrl}
\mathbf{4 a} ; \mathrm{R}=(R)-\mathrm{Et} & \mathrm{X}=-\mathrm{CH}_{2} \mathrm{CH}_{2-}, \\
\mathbf{4 b} ; \mathrm{R}=(S)-i \mathrm{Pr} & -\mathrm{CH}_{2} \mathrm{OCH}_{2}- \\
\mathbf{4 c} ; \mathrm{R}=(S)-\mathrm{CH}_{2} \mathrm{Ph} & o-\mathrm{C}_{6} \mathrm{H}_{4}
\end{array}
$$

Scheme 3. 2b was a transparent liquid and purified by vacuum distillation. ${ }^{1} \mathrm{H}$ NMR $\left(\mathrm{CDCl}_{3}\right): 0.90\left(\mathrm{t}, \mathrm{CH}_{3}, 3 \mathrm{H}\right)$, $1.2-1.8\left(\mathrm{~m}, \mathrm{CH}_{2} \mathrm{CH}_{3}, 2 \mathrm{H}\right), 3.34\left(\mathrm{t}, \mathrm{NCH}_{2}, 4 \mathrm{H}\right), 3.67(\mathrm{t}$, $\left.\mathrm{OCH}_{2} \mathrm{CH}_{2}, 4 \mathrm{H}\right), 3.8-4.5\left(\mathrm{~m}, \mathrm{CH}\right.$ and $\left.\mathrm{OCH}_{2} \mathrm{CH}, 3 \mathrm{H}\right)$. ${ }^{13} \mathrm{C} \mathrm{NMR}\left(\mathrm{CDCl}_{3}\right): 9.9\left(\mathrm{CH}_{3}\right), 29.4\left(\mathrm{CH}_{2} \mathrm{CH}_{3}\right), 45.9$ $\left(\mathrm{NCH}_{2}\right), 65.7(\mathrm{CH}), 66.3\left(\mathrm{OCH}_{2} \mathrm{CH}_{2}\right), 72.8\left(\mathrm{OCH}{ }_{2} \mathrm{CH}\right)$, $161.1(\mathrm{C}=\mathrm{N})$. IR (neat): $2952\left(v_{\mathrm{C}-\mathrm{H}}\right), 2850\left(v_{\mathrm{C}-\mathrm{H}}\right), 1650$ $\left(v_{\mathrm{C}=\mathrm{N}}\right), 1420,1273,1117,942,878 \mathrm{~cm}^{-1}$.

2c was a pale yellow solid and purified by recrystallizing from acetone. ${ }^{1} \mathrm{H}$ NMR $\left(\mathrm{CDCl}_{3}\right)$ : $0.92\left(\mathrm{t}, \mathrm{CH}_{3}\right.$, $3 \mathrm{H}), 1.3-1.9\left(\mathrm{~m}, \mathrm{CH}_{2} \mathrm{CH}_{3}, 2 \mathrm{H}\right), 3.9-4.5(\mathrm{~m}, \mathrm{CH}$ and $\left.\mathrm{OCH}_{2}, 3 \mathrm{H}\right), 4.73\left(\mathrm{~s}, \mathrm{NCH}_{2}, 4 \mathrm{H}\right), 7.25$ (s, Ar, 4H). ${ }^{13} \mathrm{C}$ NMR $\left(\mathrm{CDCl}_{3}\right): 9.9\left(\mathrm{CH}_{3}\right), 29.6\left(\mathrm{CH}_{2} \mathrm{CH}_{3}\right), 53.4$ $\left(\mathrm{NCH}_{2}\right), 66.1(\mathrm{CH}), 73.3\left(\mathrm{CH}_{2} \mathrm{O}\right), 122.6,127.3$, and $137.2(\mathrm{Ar}), 159.6(\mathrm{C}=\mathrm{N})$. IR $(\mathrm{KBr}): 2950\left(v_{\mathrm{C}-\mathrm{H}}\right), 2900$ $\left(v_{\mathrm{C}-\mathrm{H}}\right), 2860\left(v_{\mathrm{C}-\mathrm{H}}\right), 1662\left(v_{\mathrm{C}=\mathrm{o}}\right), 1586,1462,1430,1070$, $750 \mathrm{~cm}^{-1}$

2d was a pale yellow liquid and purified by vacuum distillation with a Kügel-röhr. ${ }^{1} \mathrm{H}$ NMR $\left(\mathrm{CDCl}_{3}\right)$ : 0.85 (d, $\left.\mathrm{CH}_{3}, 3 \mathrm{H}\right), 0.97\left(\mathrm{~d}, \mathrm{CH}_{3}, 3 \mathrm{H}\right), 1.5-1.8\left(\mathrm{~m}, \mathrm{CHCH}_{3}\right)$, 1H), $1.8-2.0\left(\mathrm{~m}, \mathrm{NCH}_{2} \mathrm{CH}_{2}, 4 \mathrm{H}\right), 3.2-3.5\left(\mathrm{~m}, \mathrm{NCH}_{2}\right.$, $4 \mathrm{H}), 3.6-4.3\left(\mathrm{~m}, \mathrm{CH}\right.$ and $\left.\mathrm{OCH}_{2}, 3 \mathrm{H}\right) .{ }^{13} \mathrm{C} \mathrm{NMR}$ $\left(\mathrm{CDCl}_{3}\right): 17.7\left(\mathrm{CH}_{3}\right), 19.1\left(\mathrm{CH}_{3}\right), 25.6\left(\mathrm{NCH}_{2} \mathrm{CH}_{2}\right)$, $33.4\left(\mathrm{CHCH}_{3}\right), 47.1\left(\mathrm{NCH}_{2}\right), 70.6\left(\mathrm{CH}_{2} \mathrm{O}\right.$ and $\left.\mathrm{NCH}\right)$, $159.8(\mathrm{C}=\mathrm{N})$. IR (neat): $2950,2855,1655\left(v_{\mathrm{C}=\mathrm{N}}\right), 1428$, 1263, 1077, 978, $960 \mathrm{~cm}^{-1}$.

2e was a transparent liquid and purified by vacuum distillation. ${ }^{1} \mathrm{H} \mathrm{NMR}\left(\mathrm{CDCl}_{3}\right): 1.7-2.0\left(\mathrm{~m}, \mathrm{NCH}_{2} \mathrm{CH}_{2}\right.$, $4 \mathrm{H}), 2.4-2.7(\mathrm{~m}, \mathrm{CHPh}, 1 \mathrm{H}), 3.1-3.4\left(\mathrm{~m}, \mathrm{NCH}_{2} \mathrm{CH}_{2}\right.$ and $\mathrm{CHPh}, 5 \mathrm{H}), 3.9-4.4\left(\mathrm{~m}, \mathrm{CH}_{2} \mathrm{O}\right.$ and $\left.\mathrm{NCH}, 3 \mathrm{H}\right)$, 7.1-7.2 (brs, Ph, 5H). ${ }^{13} \mathrm{C}$ NMR $\left(\mathrm{CDCl}_{3}\right): 25.6$ $\left(\mathrm{NCH}_{2} \mathrm{CH}_{2}\right), 43.1\left(\mathrm{CH}_{2} \mathrm{Ar}\right), 47.0\left(\mathrm{NCH}_{2}\right), 66.0(\mathrm{CHN}=$ C), $72.4\left(\mathrm{CH}_{2} \mathrm{OC}\right), 126.2,128.4,129.1,138.7$ (Ar), 160.2 $(\mathrm{C}=\mathrm{N})$. IR (neat): 2960, 2860, $1655\left(v_{\mathrm{C}=\mathrm{o}}\right), 1602,1478$, 1420, 1080, 976, 750, $702 \mathrm{~cm}^{-1}$.

\section{Measurements}

${ }^{1} \mathrm{H}$ NMR spectra were recorded on a $90 \mathrm{MHz}$ JEOL JNM-FX90Q NMR spectrometer. ${ }^{13} \mathrm{C}$ NMR spectra were recorded on a JEOL JNM-FX90Q NMR spectrometer operated at $22.6 \mathrm{MHz}$. IR spectra were obtained on a JASCO IR-810 infrared spectrometer. GPC analysis was performed with a Shodex 880 system using a Shodex $\mathrm{K} 804 \mathrm{~L}$ column in chloroform. Number-average molecular weights of the samples were measured by a vapor pressure osmometer (Corona Model 114) in chloroform at $35^{\circ} \mathrm{C}$. Optical rotations were measured in chloroform on a Union PM-101 polarimeter at $24^{\circ} \mathrm{C}$.

\section{Typical Procedure for the Polymerization of $\mathbf{2}$}

In a test tube equipped with a magnetic stirrer bar and three-way stopcock were placed $0.500 \mathrm{~g}(2.97 \mathrm{mmol})$ of $2 \mathrm{a}$ and $1.0 \mathrm{ml}$ of benzonitrile under nitrogen. The 
mixture was kept at $-78^{\circ} \mathrm{C}$ and $24.6 \mathrm{mg}(0.150 \mathrm{mmol})$ of methyl trifluoromethanesulfonate (triflate, MeOTf) was added to the mixture with stirring. The tube was sealed and it was kept at $120^{\circ} \mathrm{C}$ for $50 \mathrm{~h}$. Produced polymer 3a was isolated by precipitation from an equivolume mixture of diethyl ether with hexane. The pale yellow precipitate was collected by filtration. It was purified further by repeated reprecipitation from dichloromethane to the equi-volume mixed precipitant and dried in vacuo. The yield was $0.395 \mathrm{~g}(79 \%)$.

3a. ${ }^{1} \mathrm{H}$ NMR $\left(\mathrm{CDCl}_{3}\right): 0.7-1.0\left(\mathrm{CH}_{3}, 3 \mathrm{H}\right), 1.1-2.0$ $\left(\mathrm{NCCH}_{2}, 6 \mathrm{H}\right), 2.7-4.0\left(\mathrm{NCH}\right.$ and $\left.\mathrm{NCH}_{2}, 7 \mathrm{H}\right) .{ }^{13} \mathrm{C}$ NMR $\left(\mathrm{CDCl}_{3}\right): 8.5\left(\mathrm{CH}_{3}\right), 25.2\left(\mathrm{NCH}_{2} \mathrm{CH}_{2}\right), 25.5$ $\left(\mathrm{CH}_{2} \mathrm{CH}_{3}\right), 41.2$ and $43.8\left(\mathrm{NCH}_{2}\right.$ of main chain $), 48.0$ $\left(\mathrm{NCH}_{2}\right.$ of diazolidinone ring), $54.0(\mathrm{NCH}), 161.1(\mathrm{CO})$. IR (film): 2950, 2925, 2855, $1675\left(v_{\mathrm{C}=\mathrm{o}}\right), 1493,1460$, $1260,758 \mathrm{~cm}^{-1}$

3b. ${ }^{1} \mathrm{H}$ NMR $\left(\mathrm{CDCl}_{3}\right): 0.8-1.0\left(\mathrm{CH}_{3}, 3 \mathrm{H}\right), 1.1-2.0$ $\left(\mathrm{NCHCH} H_{2}, 2 \mathrm{H}\right), 2.9-3.9\left(\mathrm{NCH}, \mathrm{NCH}_{2}\right.$, and $\mathrm{OCH}_{2}$, $10 \mathrm{H}) .{ }^{13} \mathrm{C} \mathrm{NMR}\left(\mathrm{CDCl}_{3}\right): 8.3\left(\mathrm{CH}_{3}\right), 25.0\left(\mathrm{CH}_{2} \mathrm{CH}_{3}\right)$, 41.4 and $44.0\left(\mathrm{NCH}_{2}\right.$ of main chain), $49.4\left(\mathrm{NCH}_{2}\right.$ of diazolidinone ring), $55.0(\mathrm{NCH}), 69.6$ and $69.9\left(\mathrm{OCH}_{2}\right)$, $160.8(\mathrm{C}=\mathrm{O})$. IR (film): 2950, 2920, 2855, $1690\left(v_{\mathrm{C}=\mathrm{O}}\right)$, 1490, 1452, 1266, $1117 \mathrm{~cm}^{-1}$.

3c. ${ }^{1} \mathrm{H}$ NMR: $0.6-0.9\left(\mathrm{CH}_{3}, 3 \mathrm{H}\right), 1.2-1.8\left(\mathrm{CH}_{2}\right.$, $2 \mathrm{H}), 2.8-3.5\left(\mathrm{NCH}\right.$ and $\left.\mathrm{NCH}_{2}, 3 \mathrm{H}\right), 4.2-4.9\left(\mathrm{CH}_{2} \mathrm{Ar}\right.$, $4 \mathrm{H}), 7.1-7.3(\mathrm{Ar}, 4 \mathrm{H}) .{ }^{13} \mathrm{C}$ NMR: $8.4\left(\mathrm{CH}_{3}\right), 25.3$ $\left(\mathrm{CH}_{2} \mathrm{CH}_{3}\right), 42.9$ and $45.6\left(\mathrm{CH}_{2} \mathrm{Ar}\right), 47.8\left(\mathrm{NCH}_{2}\right.$ of diazolidinone ring), 54.1 ( $\mathrm{NCH}), 127.5,127.7,128.5$, 128.6, 135.1, and 136.1 (Ar), 160.5 (CO). IR (film): 3060, $2955,2925,2860,1690\left(v_{\mathrm{C}=\mathrm{o}}\right), 1492,1446,1242,754$ $\mathrm{cm}^{-1}$.

3d. ${ }^{1} \mathrm{H}$ NMR: $0.6-1.0\left(\mathrm{CH}_{3}, 6 \mathrm{H}\right), 1.3-2.4\left(\mathrm{CHCH}_{3}\right)$ and $\left.\mathrm{NCCH}_{2}, 5 \mathrm{H}\right), 2.6-3.9\left(\mathrm{NCH}\right.$ and $\left.\mathrm{NCH}_{2}\right) .{ }^{13} \mathrm{C}$ NMR: 14.2 and $17.7\left(\mathrm{CH}_{3}\right), 24.5$ and $24.8\left(\mathrm{NCCH}_{2}\right)$, $27.2\left(\mathrm{CHCH}_{3}\right), 41.3$ and $43.2\left(\mathrm{NCH}_{2}\right.$ of main chain), $43.7 \mathrm{NCH}_{2}$ of diazolidinone ring), $56.9(\mathrm{NCH}), 160.6$ $(\mathrm{C}=\mathrm{O})$. IR (film): 2950, 2925, 2860, $1680\left(v_{\mathrm{C}=\mathrm{o}}\right), 1498$, $1457,1255,755 \mathrm{~cm}^{-1}$

3e. ${ }^{1} \mathrm{H}$ NMR $\left(\mathrm{CDCl}_{3}\right): 1.2-1.7\left(\mathrm{NCCH}_{2}, 4 \mathrm{H}\right)$, $2.3-2.8\left(\mathrm{CH}_{2} \mathrm{Ph}, 2 \mathrm{H}\right), 2.8-3.5\left(\mathrm{NCH}_{2}, 6 \mathrm{H}\right), 3.5-3.9$ $(\mathrm{NCH}, 1 \mathrm{H}), 7.0-7.5(\mathrm{Ph}, 5 \mathrm{H}) .{ }^{13} \mathrm{C} \mathrm{NMR}\left(\mathrm{CDCl}_{3}\right): 25.0$ $\left(\mathrm{NCCH}_{2}\right), 38.7\left(\mathrm{CH}_{2} \mathrm{Ph}\right), 41.4$ and $43.5\left(\mathrm{NCH}_{2}\right.$ of main chain), $48.1\left(\mathrm{NCH}_{2}\right.$ of diazolidinone ring), $54.2(\mathrm{NCH})$, 126.7, 128.6, 129.1, $136.7(\mathrm{Ph}), 160.8(\mathrm{C}=\mathrm{O})$. IR (film): $2920,2848,1685\left(v_{\mathrm{C}=\mathrm{o}}\right), 1486,1450,1248,742 \mathrm{~cm}^{-1}$.

Polymers prepared by the polymerization of 2 with MeOTf (poly(2)) consisted of main-chain-type and pendant-type units.

Poly(2a). IR (film): 2955, 2920, 2860, 1678, 1623, 1446, $1410,1257,750 \mathrm{~cm}^{-1}$.

Poly(2b). IR (film): 2952, 2925, 2850, 173, 1640, 1458, $1417,1258,1117,1030,752 \mathrm{~cm}^{-1}$.

Poly(2c). IR (film): 2960, 2930, 2865, 1703, 1638, 1402 , $1360,1268,747 \mathrm{~cm}^{-1}$.

Poly(2d). IR (film): 2955, 2865, 1678, 1640 (s), 1456, $1260,754 \mathrm{~cm}^{-1}$.

Poly(2e). IR (film): 3053, 3020 (s), 2965, 2870, 1692, $1630,1492,1453,1410,1262,750 \mathrm{~cm}^{-1}$.

\section{RESULTS AND DISCUSSION}

Five optically active cyclic pseudoureas 2, $(R)$-4-ethyl-
Table I. Preparation of optically active cyclic pseudoureas ${ }^{\mathbf{a}}$

\begin{tabular}{|c|c|c|c|c|c|c|}
\hline & & Time & Product & Yield & bp & {$[\alpha]_{\mathrm{D}}^{24 \mathrm{~b}}$} \\
\hline 2-oxazoline & & $\mathrm{h}$ & 2 & $\%$ & ${ }^{\circ} \mathrm{C} / \mathrm{mmHg}$ & $\circ$ \\
\hline $4 a$ & Pyrrolidine & 2.0 & $2 a$ & 61 & $67 / 1.0$ & +38.8 \\
\hline $4 a$ & Morpholine & 3.5 & $2 \mathrm{~b}$ & 82 & $91 / 2.2$ & +39.4 \\
\hline $\mathbf{4 a}$ & Isoindoline & 4.5 & $2 c$ & 63 & $95.0^{\mathrm{c}}$ & +32.1 \\
\hline $4 b$ & Pyrrolidine & 2.0 & 2d & 44 & $101 / 0.7^{\mathrm{d}}$ & -34.4 \\
\hline $4 c$ & Pyrrolidine & 1.5 & $2 e$ & 68 & $120 / 0.3$ & +32.0 \\
\hline
\end{tabular}

${ }^{\mathrm{a}}$ In benzene under reflux. ${ }^{\mathrm{b}}$ In chloroform. ${ }^{\mathrm{c}}$ Melting point $\left({ }^{\circ} \mathrm{C}\right)$ ${ }^{\mathrm{d}}$ Distilled with a Kügel-röhr.

2-(1-pyrrolidinyl)-2-oxazoline (2a), $(R)$-4-ethyl-2-morpholino-2-oxazoline (2b), $(R)$-4-ethyl-2-(2-isoindolinyl)2-oxazoline (2c), (S)-4-isopropyl-2-(1-pyrrolidinyl)-2oxazoline (2d), and (S)-4-benzyl-2-(1-pyrrolidinyl)-2oxazoline (2e) were prepared by reactions of optically active 2-ethoxy-2-oxazolines 4 with cyclic amines as shown in Scheme 3. The results are summarized in Table I. The yields shown in the table were those after purification and the condensation reactions proceeded almost quantitatively.

\section{Polymerization of $\mathbf{2 a}$ with the Alkyl Halides}

The polymerization of $\mathbf{2 a}$ was carried out in benzonitrile using methyl iodide, benzyl bromide, or MeOTf as the initiator above $120^{\circ} \mathrm{C}$ in a sealed tube. The results of the polymerization of $\mathbf{2} \mathbf{a}$ are summarized in Table II. The polymerization of $\mathbf{2 a}$ with $0.05 \mathrm{eq}$ of methyl iodide proceeded smoothly at $120^{\circ} \mathrm{C}$ and the polymer was obtained as a pale yellow powdery material in $79 \%$ yield after heating for $50 \mathrm{~h}$ (run 1 of Table II). Spectroscopic measurements showed that the product was poly [(5ethyl-1,3-diazolidin-2-one-1,3-diyl)tetramethylene] (3a) (Scheme 4).

Figure 1 shows the ${ }^{13} \mathrm{C}$ NMR spectrum of 3a. The chemical shift for each carbon of $\mathbf{3 a}$ could be estimated from numerical addition of the shift parameter of ethyl substituent to the observed chemical shift for the corresponding carbon of the main-chain-type poly(1a). ${ }^{22}$ Each observed ${ }^{13} \mathrm{C}$ chemical shift of the seven main peaks agreed well with the corresponding value thus estimated. Assignment of peaks are shown in the figure as well as in the experimental section.

The IR spectrum of 3a is shown in Figure 2a. The presence of one strong peak at $1687 \mathrm{~cm}^{-1}$ clearly shows that 3a has only one type of carbonyl group ascribed to the 5-membered cyclic urea group because of its relatively high frequency. ${ }^{13}$

The spectroscopic data shown above as well as the ${ }^{1} \mathrm{H}$ NMR spectrum proved that the polymerization of $\mathbf{2 a}$ with methyl iodide completely proceeded via the DIP mechanism. This is in contrast to the previous result that the polymerization of $\mathbf{1 a}$ initiated by methyl iodide did not produce the pure main-chain-type polymer, but gave a polymer consisting of main-chain-type and pendanttype units at $85: 15$ (main-chain-type:pendant-type). ${ }^{13}$

The mechanism for DIP of $\mathbf{2 a}$ is considered that as shown in Scheme $\mathbf{5}$ based on that for the polymerization of 1a. First, an oxazolinium salt species 5 is formed by reaction of the monomer with the alkyl halide. Then, the counteranion of 5 , the bromide or iodide, catalyzes the 
Table II. Polymerization of $\mathbf{2} \mathbf{a}^{\mathbf{a}}$

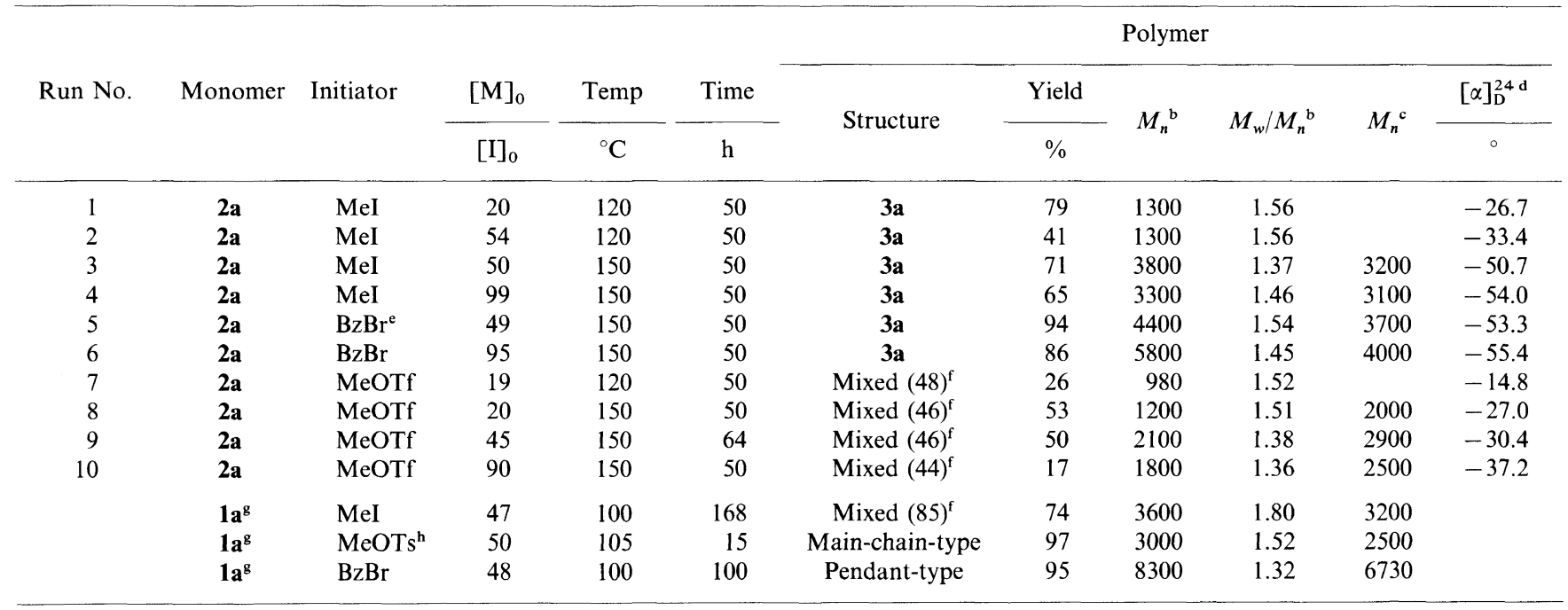

${ }^{\mathrm{a}}[\mathrm{M}]_{0}=3 \mathrm{moll}^{-1}$, in benzonitrile. ${ }^{\mathrm{b}}$ Determined by GPC with polystyrene standards. ${ }^{\mathrm{c}}$ Determined by VPO. ${ }^{\mathrm{d}}$ In chloroform. ${ }^{\mathrm{e}}$ Benzyl bromide. ${ }^{\mathrm{f}}$ The polymer consisted of main-chain-type and pendant-type units. The main-chain-type unit content is shown in parentheses. ${ }^{\mathrm{g}}$ From ref 13. ${ }^{\mathrm{h}}$ Methyl $p$-toluenesulfonate.

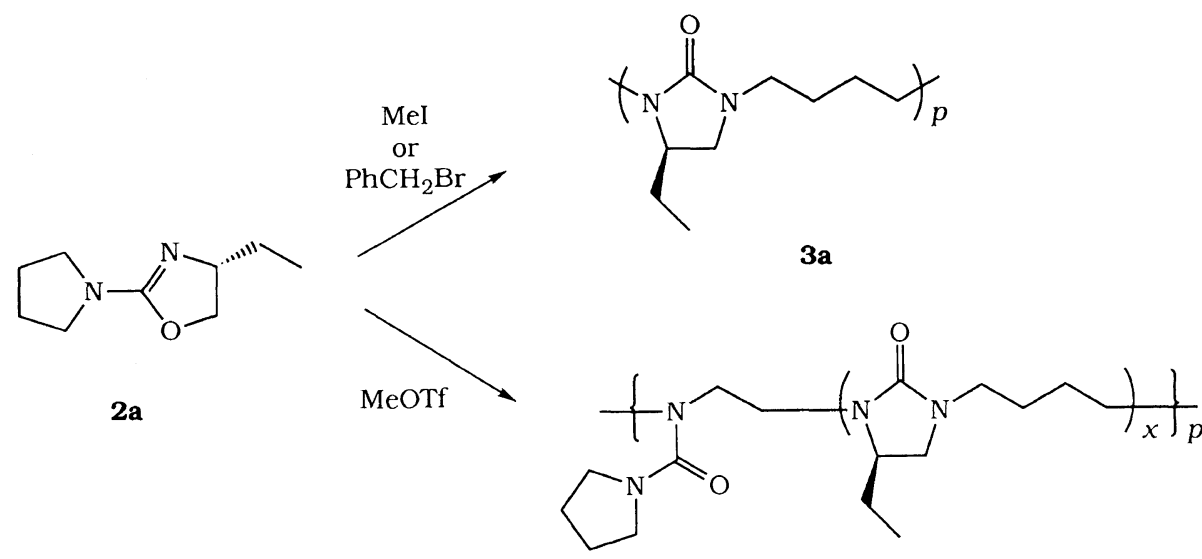

Scheme 4.

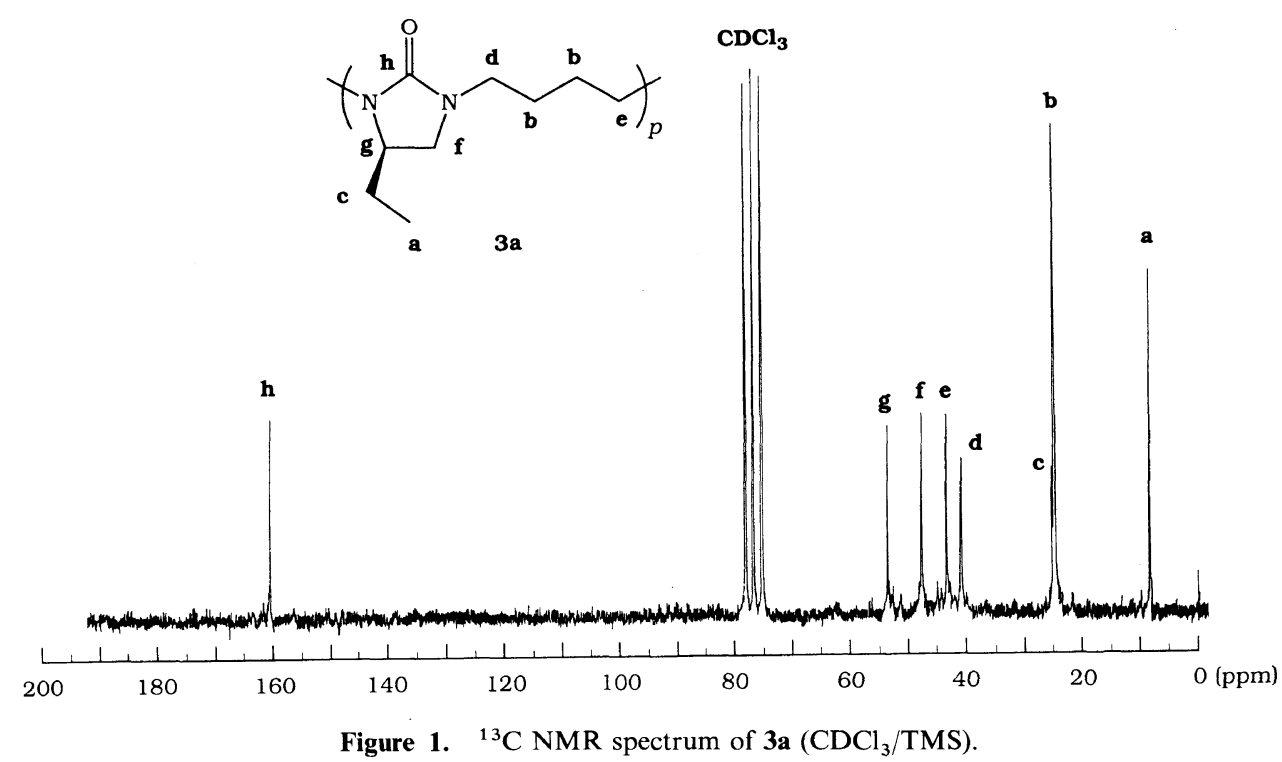

isomerization of $\mathbf{5}$ to a spiro-ammonium-type ionic species 7 via a covalent urea species $\mathbf{6}$. The reproduced halide counteranion of 7 catalyzes the isomerization of 7 to another covalent species 8 . Only step $6 \rightarrow 7$ can be considered irreversible. The attack of the monomer to 7 or 8 completes the complicated propagation in DIP. ${ }^{13}$

The key step in this DIP is the formation of 7 . If the isomerization from $\mathbf{6}$ to 7 is sufficiently rapid in comparison with the propagation from 5 to yield the pendant-type unit, the main-chain-type polymer is 
a)

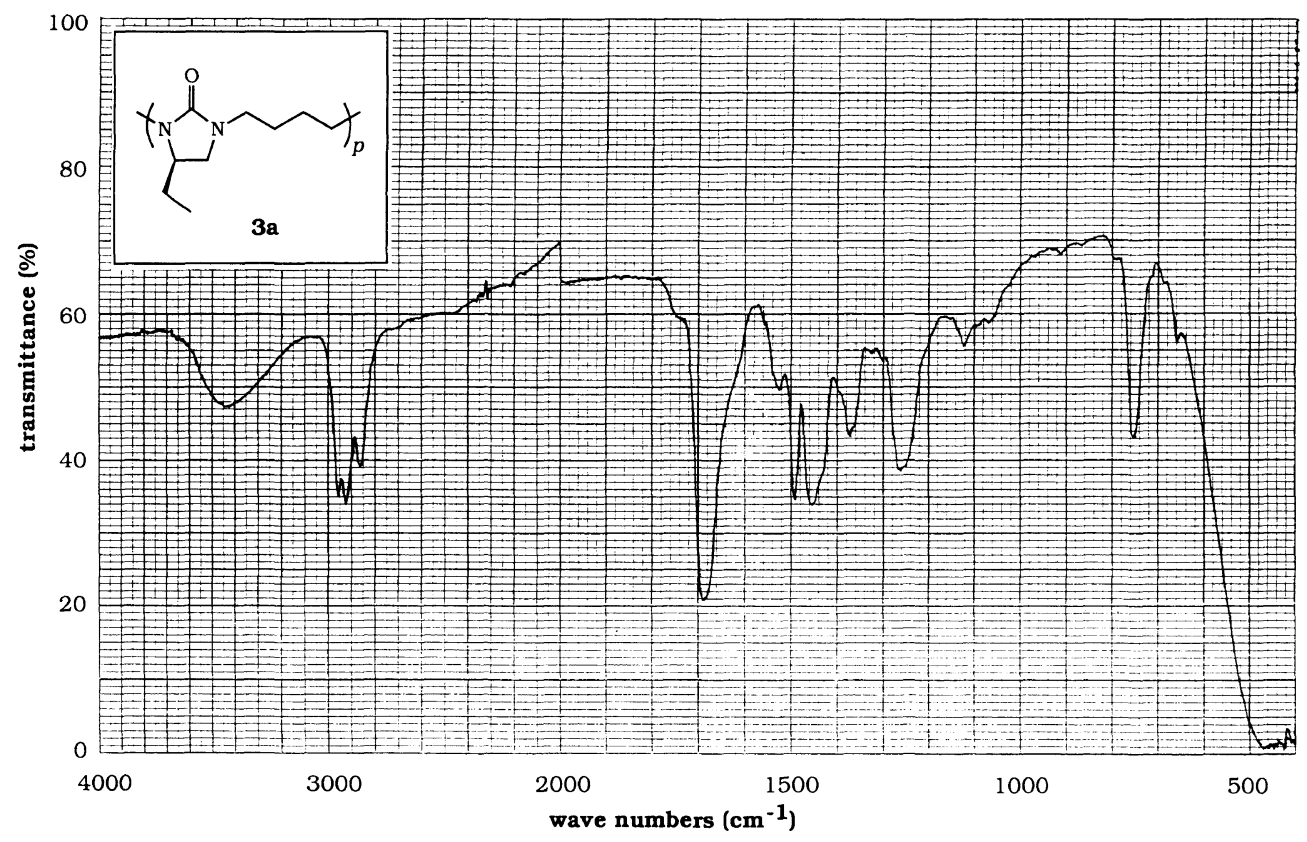

b)

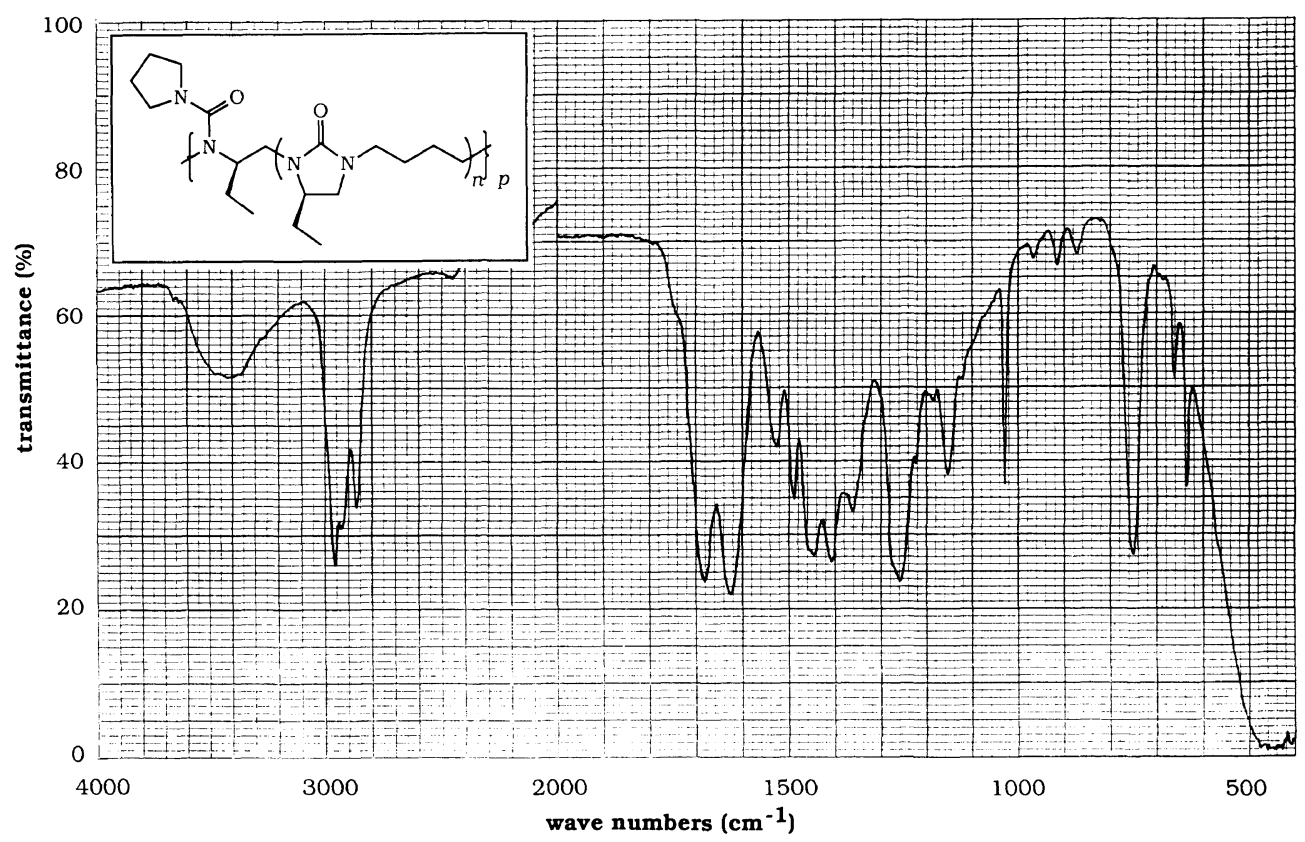

Figure 2. IR spectra of 3a (a) and poly(2a) (b) (films cast on $\mathrm{NaCl}$ plates).

formed selectively. The counter anion of high nucleophilicity readily reacts with the oxazolinium salt 5 to produce $\mathbf{6}$ and, therefore, disturbs the direct propagation from 5.

Previous studies showed that the polymer composition in DIP is influenced by the relative nucleophilicity of the counter anion of 5 to the monomer. ${ }^{13,17}$ Namely, DIP prefers a counter anion of high nucleophilicity and a monomer of low nucleophilicity. The exclusive formation of the main-chain-type polymer by the polymerization of $\mathbf{2 a}$ with methyl iodide is ascribed to the reduced nucleophilicity of $\mathbf{2 a}$ in comparison with $\mathbf{1 a}$ by the introduction of 4-ethyl substituent.

Although DIP of $2 \mathbf{a}$ proceeded at $120^{\circ} \mathrm{C}$, the polymer yield dropped from $79 \%$ to $41 \%$ when the feed ratio
$\left([\mathrm{M}]_{0} /[\mathrm{I}]_{0}\right)$ increased from 20 to 54 (run 2 in Table II) This means that the rate of polymerization is not so high at $120^{\circ} \mathrm{C}$. Therefore, the polymerization of $\mathbf{2 a}$ with a relatively high feed ratio was carried out at $150^{\circ} \mathrm{C}$. DIP of 1a proceeded at a lower temperature, at around $100^{\circ} \mathrm{C}$. Obviously, the reduced nucleophilicity of $\mathbf{2 a}$ requires a relatively high temperature for polymerization.

In the DIP of $\mathbf{2 a}$, molecular weight tended to increase with feed ratio, judging from the molecular weight determined from GPC, although the relationship was obscure. However, the molecular weights determined from VPO were generally lower than the corresponding calculated values from the feed ratio and the polymer yield. DIP has been assumed to accommodate chain 


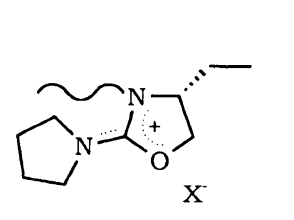

5

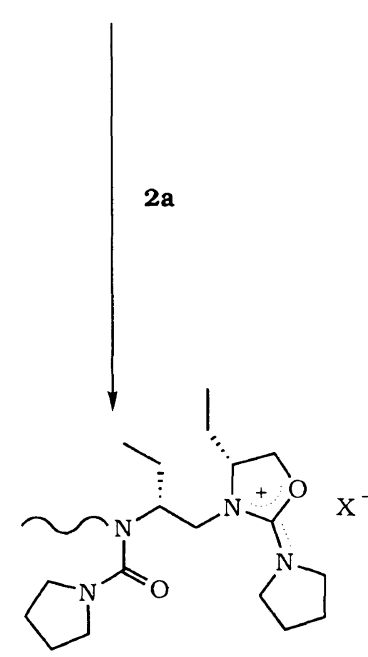

Pendant-type unit<smiles>[X]CC(CC)N(CCCC)C(=O)N1CCCC1</smiles>

6<smiles>[X]CCCCN1CC(CC)N(CCCC#C)C1=O</smiles><smiles>[Y]C1OC[C@H](CC)N1CCCCN1CC(CC)N(CCCC)C1=O</smiles>

Main-chain-type unit

Scheme 5 .

transfer. ${ }^{13}$ Presumably, chain transfer may occur in the present system.

The optical rotations of the produced polymers 3a were measured in chloroform at $24^{\circ} \mathrm{C}$. The values were around $-30^{\circ}$ for the samples whose molecular weights were 1300 (from GPC) and in the range of -50 to -56 for those of higher molecular weight. Probably, the optical rotation of the sample derives not only from the asymmetric carbon in the repeating unit, but from the higher order structure of the polymer.

In aprotic solvents, the bromide anion is more nucleophilic than the iodide ion. ${ }^{23}$ Therefore, DIP generally proceeds more selectively with benzyl bromide than with methyl iodide. In the DIP of $\mathbf{2 a}$, polymer yield and molecular weight were generally higher in runs with benzyl bromide than in those with methyl iodide, although no difference was observed in polymer composition since pure 3a was obtained even by polymerization with methyl iodide.

\section{Polymerization of 2a with MeOTf}

The polymerization of 2a with MeOTf yielded an optically active polymeric material in a low or moderate yield, whose values of optical rotation were -15 to $-37^{\circ}$. The resulting polymer was not pure poly $[N-(1-$ pyrrolidinylcarbonylimino)-1-( $R)$-ethylethylene] (pendant-type polymer), but consisted of pendant-type and main-chain-type units.

Polymer composition could be determined from neither ${ }^{1} \mathrm{H}$ nor ${ }^{13} \mathrm{C}$ NMR spectroscopy. The signals in its $90 \mathrm{MHz}{ }^{1} \mathrm{H}$ NMR spectrum were very broad and the ${ }^{13} \mathrm{C}$ NMR spectrum was so complicated by the presence of the two units as well as its relatively low molecular weight that exact peak assignment could not be performed.
The composition of the polymer was roughly estimated from IR spectroscopy. The IR spectrum of the polymer of 2a prepared with MeOTf is shown in Figure $2 \mathrm{~b}$. In the spectrum, two carbonyl peaks are observed at 1687 and $1625 \mathrm{~cm}^{-1}$, each was ascribed to the carbonyl groups of the main-chain-type and pendant-type units in the polymer respectively. The relative ratio of the absorbances of two carbonyl peaks was measured and the value was applied to the calibration curve prepared from mixtures of the pure pendant-type and main-chaintype poly(1a)s. We used poly(1a)s instead of poly(2a)s since the pure pendant-type poly(2a) could not be prepared. The observed main-chain-type unit contents were, therefore, of rough estimation and around $45 \%$.

DIP of cyclic pseudourea with the alkyl halide initiator sometime yields a polymer consisting of pendant-type and main-chain-type units. In the present case, however, a polymer of mixed composition was produced by the polymerization of $\mathbf{2 a}$ with MeOTf, which produces a non-nucleophilic triflate anion. This is the first example that the polymerization of cyclic pseudourea with MeOTf yields a polymer containing the main-chain-type unit.

DIP can be catalyzed by any species present in the system even if it has an adequate nucleophilicity and adequate ability as the leaving group. Weak nucleophiles being present in the system, the solvent and the once produced pendant-type polymer itself, may catalyze the DIP of $\mathbf{2 a}$ instead of the halide ion. However, this explanation does not coincide with the previous results that no contamination of the pendant-type unit has been observed in the polymerization of 1 with MeOTf until now.

Polymerization always accommodates depolymerization to some extent. In the ring-opening polymerization 

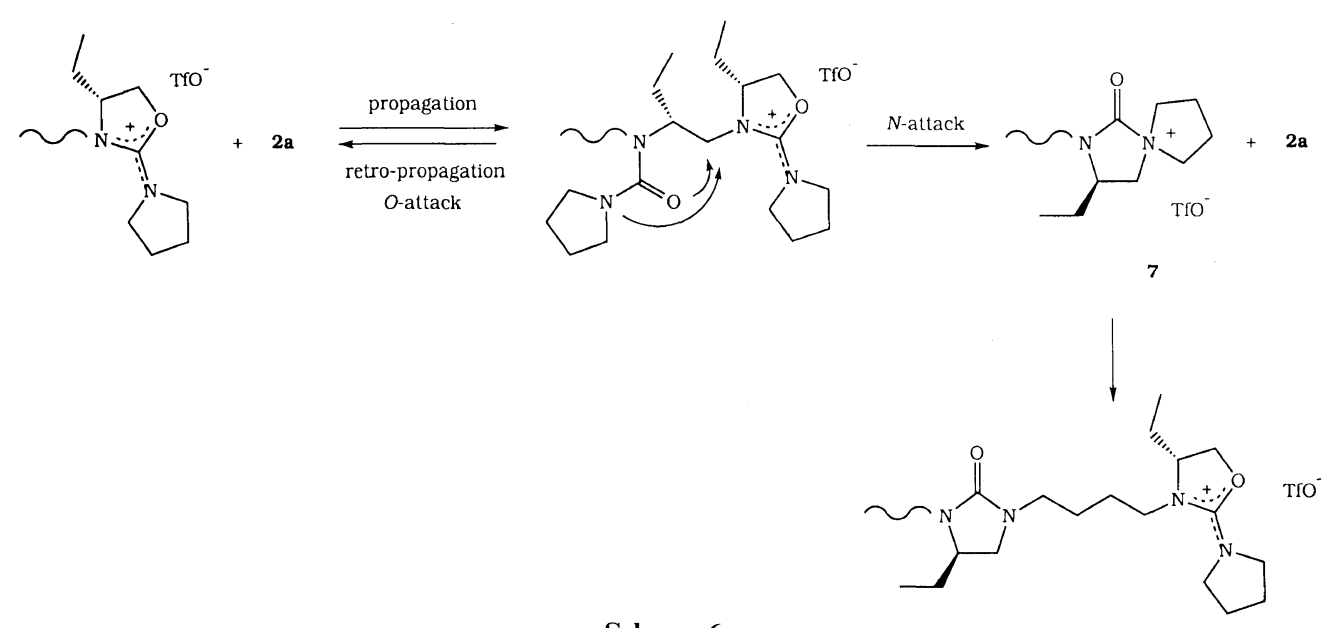

Scheme 6 .

of cyclic pseudourea, the propagation is an $S_{\mathrm{N}} 2$ reaction, in which the monomer is the nucleophile and the urea moiety is the leaving group. The introduction of 4substituent to the oxazoline ring reduces the thermodynamical advantage of propagation and, therefore, enhances the rate of depolymerization, in which the penultimate urea group attacks the methylene carbon adjacent to the oxazolinium end and the monomer leaves to reproduce the oxazolinium end of the next lower DP (Scheme 6). Although the propagation is more favorable than depolymerization, the latter occurs at a significant rate. Occasionally, the nucleophilic attack of the penultimate urea group occurs at its nitrogen atom, which irreversibly produces the spiroammonium type propagating end 7 and subsequent propagation from 7 forms the main-chain-type unit.

The formation of 7 during the polymerization was confirmed from the in situ ${ }^{13} \mathrm{C}$ NMR spectrum of the polymerization system where the $[\mathrm{M}]_{0} /[\mathrm{I}]_{0}$ ratio was set at 5 . With the progress of the polymerization, signals ascribed to propagating species were observed at $\delta 151.6$ and 154.2. These signals were ascribed to the carbonyl carbons of 7 and the oxazolinium type propagating species, respectively. ${ }^{13,14}$

Although we have no evidence to support the hypothetical mechanism that 7 is formed by depolymerization, the polymerization behavior of $\mathbf{2 a}$ as well as other 2 monomers can be explained well by assuming this. This type of, so to speak, "self-catalyzed DIP" should be possible in any polymerization of $\mathbf{1}$. However, depolymerization is considered to be negligible in the polymerization of the monomers having no 4-substituent and, hence, it has not been observed until now.

\section{DIP of Other 2 Monomers}

DIP of other monomers, $\mathbf{2} \mathbf{b}-\mathbf{e}$, with methyl iodide or benzyl bromide proceeded. The results are shown in Table III. IR and NMR spectroscopic measurements revealed that the produced polymers were exclusively of the main-chain-type (see experimental section). Product yields were $80-100 \%$ in runs using $2 \mathbf{c}$ or $2 \mathbf{e}$ as monomer, but significantly lower in runs with $\mathbf{2 b}$ and with $\mathbf{2 d}$.

The reason for the low yield of poly $(\mathbf{2} \mathbf{b})$ is ascribed to the poor nucleophilicity of $\mathbf{2 b}$. The previous study on the polymerization of 2-morpholino-2-oxazoline (1b) indicated that $\mathbf{1 b}$ was less nucleophilic than 1a. That the presence of the electronegative oxygen atom in the morpholine ring reduced the nucleophilicity of $\mathbf{1 b}$ is the reason for this. The six-membered structure of the morpholine ring was also considered to reduce nucleophilicity because of steric hindrance. ${ }^{13}$ These explanations are applicable to the present case of $\mathbf{2} \mathbf{b}$.

The relatively low yields in the runs with $\mathbf{2 d}$ are due to the reduced nucleophilicity of $\mathbf{2 d}$ by the introduction of the relatively bulky isopropyl group. GPC measurements showed that the molecular weights of the products were generally low in runs using $\mathbf{2 d}$. The introduction of an isopropyl group reduces the nucleophilicity of 2d, keeping its basicity. As monomer nucleophilicity decreases, proton abstraction by the monomer occurs more frequently, which leads to chain-transfer.

The most probable pathway of racemization is abstraction of the proton attached to the asymmetric carbon by the monomer. If this type of racemization takes place during DIP, optical rotation will decrease with the reaction temperature or reaction time. However, the individual values of optical rotation for the samples were not so much influenced by these experimental conditions. This suggests that DIP of $\mathbf{2}$ proceeds without racemization.

\section{Polymerization of Other 2 Monomers with MeOTf}

The contamination of the main-chain-type unit in the produced polymer was observed in the polymerization of the other 2 monomers with MeOTf. The results are shown in Table III; polymer composition was determined by applying a calibration curve prepared from mixtures of the pure pendant-type and main-chain-type poly(1b)s to poly(2b) and that prepared from poly(1a)s to $\operatorname{poly}(\mathbf{2} \mathbf{c}-\mathbf{e})$. The content of the main-chain-type unit in the product was not so much influenced by polymerization conditions, but strongly depended on monomer structure. For example, the polymerization of $\mathbf{2 c}$ gave a polymer containing $c a .12 \%$ of the main-chain type unit, while the polymer derived from $\mathbf{2 d}$ contained ca. $83 \%$ of the main-chain-type unit.

The difference in the polymer compositions prepared from $\mathbf{2 b}$ and from $\mathbf{2 d}$ can be explained by depolymerization. The results of DIP of $\mathbf{2} \mathbf{d}$ above suggests the poor nucleophilicity of $\mathbf{2 d}$, which reduces the rate of propagation in its polymerization with MeOTf. On the other hand, the steric influence of the isopropyl substituent on 
Table III. Polymerization of other cyclic pseudoureas ${ }^{\mathrm{a}}$

\begin{tabular}{|c|c|c|c|c|c|c|c|c|c|c|}
\hline \multirow{3}{*}{ Monomer } & \multirow{3}{*}{ Initiator } & \multirow{3}{*}{$\frac{[\mathrm{M}]_{0}}{[\mathrm{I}]_{0}}$} & \multirow{3}{*}{$\frac{\text { Temp }}{{ }^{\circ} \mathrm{C}}$} & \multirow{3}{*}{$\frac{\text { Time }}{\mathrm{h}}$} & \multicolumn{6}{|c|}{ Polymer } \\
\hline & & & & & Yield & \multirow{2}{*}{$M_{n}^{\mathrm{b}}$} & \multirow{2}{*}{$M_{w} / M_{n}{ }^{\mathrm{b}}$} & \multirow{2}{*}{$M_{n}^{\mathrm{c}}$} & \multirow{2}{*}{$\begin{array}{c}\text { Content of main- } \\
\text { chain-type unit }\end{array}$} & \multirow{2}{*}{$\frac{[\alpha]_{\mathrm{D}}^{24 \mathrm{~d}}}{0}$} \\
\hline & & & & & $\%$ & & & & & \\
\hline $2 b$ & MeI & 20 & 120 & 50 & 66 & 2200 & 1.48 & & 100 & -16.6 \\
\hline $2 b$ & MeI & 20 & 150 & 50 & 79 & 1700 & 1.21 & & 100 & -19.0 \\
\hline $2 \mathbf{b}$ & MeI & 48 & 120 & 50 & 32 & 1900 & 1.48 & 2600 & 100 & -18.2 \\
\hline $2 \mathbf{b}$ & MeI & 41 & 150 & 50 & 68 & 2400 & 1.27 & & 100 & -19.0 \\
\hline $\mathbf{2 b}$ & $\mathrm{MeI}$ & 87 & 150 & 50 & 42 & 2700 & 1.19 & 1900 & 100 & -19.4 \\
\hline $2 \mathbf{b}$ & MeOTf & 20 & 150 & 50 & 15 & 650 & 1.36 & 1300 & $33^{\mathrm{e}}$ & -28.1 \\
\hline $2 b$ & MeOTf & 56 & 150 & 50 & 2 & 1100 & 1.38 & & $32^{\mathrm{e}}$ & -33.6 \\
\hline $2 c$ & MeI & 20 & 120 & 50 & 98 & 4600 & 1.56 & 3600 & 100 & -27.1 \\
\hline $2 c$ & MeI & 98 & 150 & 50 & 100 & 5400 & 1.71 & 3600 & 100 & -28.0 \\
\hline $2 c$ & MeOTf & 20 & 150 & 50 & 55 & 1300 & 1.36 & 1500 & $12^{\mathrm{f}}$ & -3.3 \\
\hline 2d & MeI & 20 & 150 & 50 & 63 & 1300 & 1.33 & 1500 & 100 & +32.4 \\
\hline 2d & MeI & 103 & 150 & 300 & 35 & 1300 & 1.36 & 1100 & 100 & +40.5 \\
\hline 2d & $\mathrm{BzBr}$ & 82 & 150 & 300 & 37 & 1500 & 1.39 & 1500 & 100 & +40.5 \\
\hline 2d & MeOTf & 20 & 150 & 50 & 41 & 1200 & 1.22 & 1600 & $83^{\mathrm{f}}$ & +38.3 \\
\hline $2 d$ & MeOTf & 20 & 150 & 300 & 45 & 1200 & 1.32 & 1000 & $83^{\mathrm{f}}$ & +32.9 \\
\hline $2 e$ & MeI & 19 & 150 & 50 & 94 & 3400 & 1.47 & 2200 & 100 & +71.4 \\
\hline $2 e$ & MeI & 94 & 150 & 300 & 84 & 3800 & 1.61 & 2500 & 100 & +69.3 \\
\hline $2 e$ & $\mathrm{BzBr}$ & 20 & 150 & 50 & 90 & 3900 & 1.35 & 2100 & 100 & +71.9 \\
\hline $2 e$ & $\mathrm{BzBr}$ & 72 & 150 & 300 & 82 & 4900 & 1.44 & 2300 & 100 & +67.3 \\
\hline $2 e$ & MeOTf & 18 & 150 & 50 & 97 & 1800 & 1.21 & 2200 & $46^{\mathrm{f}}$ & +36.6 \\
\hline $2 e$ & MeOTf & 99 & 150 & 300 & 57 & 3500 & 1.32 & 3000 & $39^{\mathrm{f}}$ & +43.0 \\
\hline
\end{tabular}

${ }^{\mathrm{a}}[\mathrm{M}]_{0}=3 \mathrm{moll}^{-1}$, in benzonitrile, at $150^{\circ} \mathrm{C}$. ${ }^{\mathrm{b}}$ Determined by GPC with polystyrene standards. ${ }^{\mathrm{c}}$ Determined by VPO. ${ }^{\mathrm{d}}$ In chloroform. ${ }^{\mathrm{e}}$ Polymer composition was determined from IR spectroscopy, applying the calibration curve prepared from poly(1b). ${ }^{\mathrm{f}}$ Polymer composition was determined from IR spectroscopy, applying the calibration curve prepared from poly(1a).

the rate of depolymerization is considered to be relatively small. Therefore, the relative rate of depolymerization increases, which results in increase of the mainchain-type unit in the product.

The contamination of main-chain-type unit is relatively small in runs using $\mathbf{2 c}$. The steric effect of $o$-phenylene ring on the nucleophilicity of the monomer is small since it is situated apart from the nucleophilic center. Actually, the previous study showed that the polymerizability of 2-(2-indolinyl)-2-oxazoline (1c) is similar to that of 1a. On the other hand, the rate of the depolymerization, i.e., the rate of attack of the penultimate urea group to the methylene carbon adjacent on the oxazolinium rings significantly influenced by the $o$ phenylene ring attached to the oxazolonium end. Therefore, the rate of depolymerization is considerably suppressed, which reduces the main-chain-type content in the product.

Acknowledgment. The authors gratefully acknowledge the Asahi Glass Foundation for financial support of this work.

\section{REFERENCES}

1. Y. Okamoto and T. Nakano, Chem. Rev., 94, 349 (1994).

2. A. Bur and L. J. Fetters, Chem. Rev., 76, 727 (1976).

3. Y. Okamoto, M. Matsuda, T. Nakano, and E. Yashima, Polym. J., 25, 4142 (1993).

4. F. Millich, Macromol. Rev., 15, 207 (1980).

5. Y. Itoh, E. Ihara, and M. Murakami, Polym. J., 24, 297 (1992).

6. T. Saegusa, S. Kobayashi, and M. Ishiguro, Macromolecules, 7, 958 (1974).
7. T. Saegusa, T. Hirao, and Y. Ito, Macromolecules, 8, 87 (1975).

8. M. Goodman, Y. Nishiuchi, and T. Yamazaki, 1, Preprints, 1st Pacific Polymer Conference, Maui, Hawaii, U.S.A., December 12-15, Organiged Pacific Polymer Federation, 1989, p 427.

9. A. Levy and M. Litt, J. Polym. Sci., $A-1,6,57$ (1968).

10. D. A. Tomalia and D. P. Sheetz, J. Polym. Sci., A-1, 4, 2253 (1966).

11. S. Kobayashi, K. Morikawa, N. Shimizu, and T. Saegusa, Polym. Bull., 11, 253 (1984).

12. K. J. Ivin and T. Saegusa, "Ring-Opening Polymerization," Vol. 1, Elsevier Applied Science Publishers, London, 1985, Chapter 1.

13. M. Miyamoto, K. Aoi, S. Yamaga, and T. Saegusa, Macromolecules, 25, 5111 (1992). M. Miyamoto, M. Shimakura, K. Tsutsui, K. Hasegawa, K. Aoi, S. Yamaga, and T. Saegusa, Macromolecules, 26, 7116 (1993).

14. M. Miyamoto, M. Morimoto, and T. Saegusa, Polym. J., 25, 1133 (1993).

15. M. Miyamoto, H. Amii, K. Aoi, and T. Saegusa, Macromolecules, 26, 1474 (1993).

16. M. Miyamoto, M. Shimakura, S. Shimoda, and K. Hasegawa, Polym. J., 27, 469 (1995).

17. M. Miyamoto and Y. Harada, Kobunshi Ronbunshu, 52, 546 (1995) (in Japanese).

18. H. Meerwein, "Organic Synthesis," Coll. Vol. 5, John Wiley \& Sons, New York, N.Y., 1973, p 1080.

19. D. A. Dickman, A. I. Meyers, G. A. Smith, and R. E. Gawley, "Organic Synthesis," Coll. Vol. 7, John Wiley \& Sons, New York, N.Y., 1990, p 530.

20. K.-H. Scholz, H.-G. Heine, and W. Hartmann, "Organic Synthesis," Coll. Vol. 7, John Wiley \& Sons, New York, N.Y., 1990, p 4.

21. K. Rein, M. Goicoechea-Pappas, T. V. Anklar, G. C. Hart, and G. A. Smith, J. Am. Chem. Soc., 111, 2211 (1989).

22. R. M. Silverstein, G. C. Bassler, and T. C. Morrill, "Spectroscopic Identification of Organic Conpounds," 5th ed, John Wiley \& Sons, New York, N.Y., 1991, Chapter 5.

23. A. J. Parker, Chem. Rev., 69, 1 (1969). 